fulfill the role of a reference book for these parts of the subject that interest the student.

Sadly this book fills neither role. Mistakes such as the biceps being connected to the humerus together with instructions to 'feel your oral cavity' and a haranging text 'don't you find it interesting that', make the book hard to recommend as do statements that reveal an ignorance of modern literature e.g. 'primitive neurons seem almost to be programmed individually each to move and direct its axon along an elaborately predetermined course'.

P. N. Dilly

St George's Hospital,

Medical School,

London SW17 ORE.

Hepatocellular carcinoma. A series of workshops on the biology of human cancer

Report No. 17. Edited by KUNIO OKUDA and IAN MACKAY. UICC Technical Report Series. Vol. 74. Pp. 204. International Union against Cancer, Geneva (distributed by Hans Huber, Bern, Switzerland), 1983. Sw.Fr. 44.00.

Hepatocellular carcinoma is very much in the news at the moment, being at the forefront of the revival of interest in viral carcinogenesis, and being confidently expected to be the first major human tumour to be preventable by vaccination. This monograph compiled by 12 leading workers in the field and edited by Okuda and Mackay under the auspices of the International Union against Cancer in Geneva in 1982 is therefore timely. However, to the credit of the editors, epidemiology, human and animal pathology, and putative aetiological factors other than hepatitis B virus (HBV) such as chemical carcinogenesis, cirrhosis and diet also receive detailed consideration.

It is a shame perhaps that the workshop did not extend into the area of treatment where review and analysis of current therapy and guidelines for future research are urgently needed. Nonetheless it is a sign of the pace of current research that one of the recommendations for future study, namely, vaccination and/or administration of hyperimmune globulin at the time of birth to infants born of HBV carrier mothers has recently been reported to have been successfully accomplished.

The book is marked both by its clarity and brevity. In just 150 pages, liberally illustrated with tables and diagrams, the 'state of the art is reviewed', and there is no better available launching pad for a worker wishing to enter this field.

R. Williams

King's College Hospital, London SE5 9RS.

An International Survey of Distributions of Histologic Types of Tumours of the Testis and Ovary

Edited by Helge Stalsberg. UICC Technical Report Series, Vol. 75. Pp. $x+353$, illustrated. International Union Against Cancer, Geneva (Distributed by Hans Huber, Bern, Switzerland). Sw.fr.48.00, \$24.00.

The purpose of this book is to document the incidence of tumours of the testis and ovary in selected countries throughout the world. This is done in the form of contributions from pathologists, oncologists and epidemiologists from each area with an overall discussion at the end of each section by the editors. The sections on tumours of the testis and tumours of the ovary are each preceded by a discussion of the classification of these tumours which pathologists will find useful. There are, however, very few illustrations, those present being restricted to one chapter on the histological typing of ovarian cancer. Several interesting points arise out of the section on testicular tumours, including the low incidence in South America and the low incidence in blacks overall. The large British series is alone in demonstrating the important fact that the incidence of testicular tumours appears to be increasing. The section of the book devoted to ovarian tumours is much more difficult to come to grips with due to the complex histology of these tumours. The place for this book is in the large medical library rather than in the individual or even departmental collection but this is not to detract from its value as a reference work for those interested in tumours of the gonads.

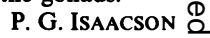
University College, $C$ London WCIE 7JJ. $\Rightarrow$

Edited by C. A. CorR and D. M. CoRR. Pp. xix +364 , illustrated. Faber and Faber, London, 1983. $£ 4.95$ (paperback).

The American authors of this book, a professor of Humanities and his wife, a teacher of Nursing, present it as a 'Comprehensive $\vec{\circ}$ resource for caregivers and students. While it has several contributions from authors in the U.K., where modern concepts of hospice $\vec{\omega}$ care originated, it is clearly intended as a general introduction to the Hospice Movement in the U.S.A. and, like any book that covers a wide range of disciplines, it possibly fails in not being sufficiently
detailed in any one of them.

Chapters by Dr Robert Twycross and Dr Mary Baines describe $\dot{\theta}$ their pioneer work on scientific pain control, but omit their more recent work on the control of nausea and vomiting, which can often $\bigcirc$ be quite as distressing as pain. Mary Cockburn writes a practical and helpful summary of nursing care, which should be compulsory reading for doctors, who sometimes forget that it is good nursing that $\infty$ matters most to the dying. Finally there is a valuable contribution? from Averil Stedeford on Psychotherapy of the Dying Patient. This difficult area has perhaps been neglected up to now. How do you support a patient who is dying angrily?

The editors state that 'Hospice is a philosophy and not a facility'. There are many doctors in the U.K. who cannot accept such a broad $\vec{D}$ claim, but do acknowledge the great value of practical teaching and $\vec{\oplus}$ exemplary care by hospices.

\section{An Introduction to Community Medicine}

By Charles du V. Florey, Peter Burney, Michael D'Souza, $\overline{0}$ Ellie SCRIVens and Peter West. Pp. vi +134 , illustrated. Churchill Livingstone, Edinburgh, London, Melbourne, New York, 1983. £3.95.

The book sets out to give an overview of the subject of community medicine to medical students. The chapters pass through the sequence of dealing with a community health problem; epidemiological investigation, assessment of answer, implementation of a solution through policy making and management systems.

The early chapters suffer from the limited space available. In $\delta$ particular a rather restricted view of epidemiology is presented to the student. However the use of the subject of air pollution, in which the authors have expert knowledge, as an example throughout the book $\mathcal{}$ makes up to some extent for these shortcomings. One or two points $D$ of emphasis seem strange-for instance tolylene diisocyanate asthma and tartrazine urticaria as examples of illnesses of the modern environment.

The strength of the book lies in the last two chapters which deal with government policy and its making. This is an area where $N$ undergraduate education is in general poor and this book will be of $\mathrm{N}$ benefit. Overall as an introduction to the subject the book is useful. $\sigma$ However all students would need to supplement it with reading in epidemiology and statistics to gain the necessary basic foundation ofo knowledge.

A. J. HALL

MRC Environmental Epidemiology Unit, Southampton General Hospital, Southampton SO9 4XY. 을 